\title{
Conceptual Design of a CERMET NTR Fission Core Using Multiphysics Modeling Techniques
}

\section{AIAA Joint Propulsion Conference}

\author{
Jonathan A. Webb \\ Brian J. Gross \\ William T. Taitano
}

\section{August 2011}

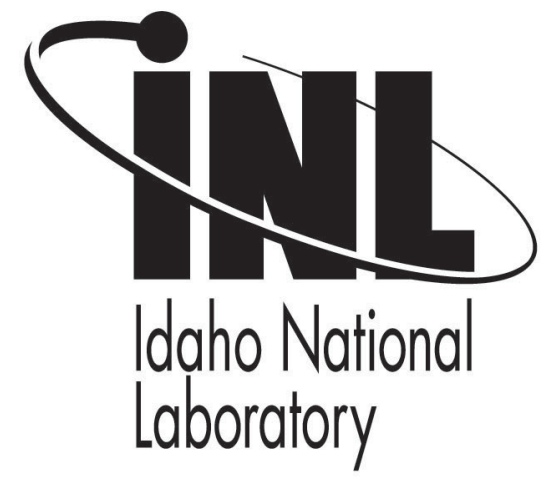

This is a preprint of a paper intended for publication in a journal or proceedings. Since changes may be made before publication, this preprint should not be cited or reproduced without permission of the author. This document was prepared as an account of work sponsored by an agency of the United States Government. Neither the United States Government nor any agency thereof, or any of their employees, makes any warranty, expressed or implied, or assumes any legal liability or responsibility for any third party's use, or the results of such use, of any information, apparatus, product or process disclosed in this report, or represents that its use by such third party would not infringe privately owned rights. The views expressed in this paper are not necessarily those of the United States Government or the sponsoring agency. 


\title{
Conceptual Design of a CERMET NTR Fission Core Using Multiphysics Modeling Techniques
}

\author{
Jonathan A. Webb* and Brian J. Gross * \\ Idaho National Laboratory, Idaho Falls, ID, 83401, U.S.A. \\ William T. Taitano ${ }^{\dagger}$ \\ University of New Mexico, Albuquerque, 87131, U.S.A.
}

\begin{abstract}
An initial pre-concenptual CERMET Nuclear Thermal Propulsion reactor system is investigated within this paper. Reactor configurations are investigated where the fuel consists of $60 \mathrm{vol} . \% \mathrm{UO}_{2}$ and $40 \mathrm{vol} . \% \mathrm{~W}$ where the $\mathrm{UO}_{2}$ consists of $\mathrm{Gd}_{2} \mathrm{O}_{3}$ concentrations of 5 and $10 \mathrm{~mol} . \% \cdot \mathrm{Gd}_{2} \mathrm{O}_{3}$. The fuel configuration consisting of $5 \mathrm{~mol} . \% \mathrm{UO}_{2}$ was found to have a total mass of $2761 \mathrm{~kg}$ and a thrust to weight ratio of 4.10 and required a coolant channel surface area to fueled volume ratio of approximately 15.0 in order to keep the centerline temperature below $3000 \mathrm{~K}$. The configuration consisting of $10 \mathrm{~mol} \% \mathrm{Gd}_{2} \mathrm{O}_{3}$ required a surface area to volume ratio of approximately 12.2 to cool the reactor to a peak temperature of $3000 \mathrm{~K}$ and had a total mass of $3200 \mathrm{~kg}$ and a thrust to weight ratio of 3.54 . It is not known yet what concentration of $\mathrm{Gd}_{2} \mathrm{O}_{3}$ is required to maintain fuel stability at $3000 \mathrm{~K}$; however, both reactors offer the potential for operations at 25,000 $\mathrm{lb}_{f}$ and and at a specific impulse which may range from 900 to 950 seconds.
\end{abstract}

\section{Nomenclature}

$g \quad$ Gravitational acceleration, $9.81 \mathrm{~m} / \mathrm{s}^{2}$

$I_{s p} \quad$ Specific Impulse, $\mathrm{s}$

$k$ Thermal conductivity, $\mathrm{W} / \mathrm{m} \cdot \mathrm{k}$

$k_{\text {eff }}$ Neutron multiplication number

$R \quad$ Specific gas constant, $\mathrm{J} / \mathrm{kg} \cdot \mathrm{K}$

$T$ Temperature, $\mathrm{K}$

$u \quad$ velocity vector, $\mathrm{m} / \mathrm{s}$

$P_{c} \quad$ Chamber pressure, $\mathrm{MPa}$

$P_{e} \quad$ Nozzle exit pressure, $\mathrm{MPa}$

$\dot{Q} \quad$ Energy transfer rate, $\mathrm{W} / \mathrm{s}$

$\gamma \quad$ Ratio of specific heats

$\epsilon \quad$ Nozzle throat to exit area ratio

$\rho$ Density, $\mathrm{g} / \mathrm{cm}^{3}$

$\tau$ Shear stress, $\mathrm{N} / \mathrm{m}^{2}$

\section{Introduction}

Robust manned space exploration as well as unmanned space exploration is limited by the ability to rapidly transport payloads between different celestial targets. Nuclear Thermal Propulsion (NTP) has been proposed as a near term achievable method of propelling a spacecraft at high thrust and a high specific impulse. ${ }^{1}$ Described as simply as possible, an NTP engine consists of a fission reactor comprised of refractory

*Research Scientist, Space Nuclear Systems and Technology, 1765 N. Yellowstone Hwy., AIAA Member.

$\dagger^{\dagger}$ Graduate Student, Department of Nuclear Engineering, 1 University of New Mexico, NM, 87131 
materials which is heated to a maximum possible temperature without melting. A low molecular mass working fluid such as hydrogen is pumped through coolant channels in the reactor absorbing enthalpy from the reactor system. The hydrogen is fed into a converging-diverging rocket nozzle where the fluid enthalpy is converted into kinetic energy which produces thrust.

The performance of an NTR engine can be determined as a function of the nozzle area ratio, hydrogen chamber temperature and hydrogen chamber pressure. ${ }^{2}$ The specific impulse can be determined via Equation 1 where $I_{s p}$ represents the specific impulse, $g$ represents the gravitational constant of $9.81 \mathrm{~m} / \mathrm{s}^{2}$, $\gamma$ represents the ratio of specific heats, $P_{c}$ represents the hydrogen chamber pressure, $P_{e}$ represents the hydrogen pressure at the nozzle exit and $R$ represents the specific gas constant for hydrogen.

$$
I_{s p}=\frac{1}{g} \sqrt{\frac{2 \gamma}{\gamma-1} R T\left[1-\left(\frac{P_{e}}{P_{c}}\right)^{\frac{\gamma-1}{\gamma}}\right]}
$$

The hydrogen pressure at the nozzle exit can be determined by numerically solving Equation 2 with knowledge of the hydrogen chamber pressure and the ratio of the nozzle exit to throat area $(\epsilon)$.

$$
\left(\frac{1}{\epsilon}\right)=\left(\frac{\gamma-1}{2}\right)^{\frac{1}{\gamma-1}}\left(\frac{P_{e}}{P_{c}}\right)^{\frac{1}{\gamma}} \sqrt{\frac{\gamma+1}{\gamma-1}\left[1-\left(\frac{P_{e}}{P_{c}}\right)^{\frac{\gamma-1}{\gamma}}\right]}
$$

Figure 1 demonstrates the specific impulse that would be obtained for an NTR engine with a hydrogen chamber temperature ranging from $1000 \mathrm{~K}$ to $3200 \mathrm{~K}$ and a chamber pressure of $4.5 \mathrm{MPa}$ at nozzle ratios ranging from 20 to infinity. Figure 1 clearly demonstrates the advantage of increasing the hydrogen chamber temperature on the performance of an NTR engine; however, it is also clear that refractory materials are required to sustain temperatures approaching and possibly even exceeding $3000 \mathrm{~K}$. In theory achieving a specific impulse in the range of 900 to 950 seconds may be possible with near term technology.

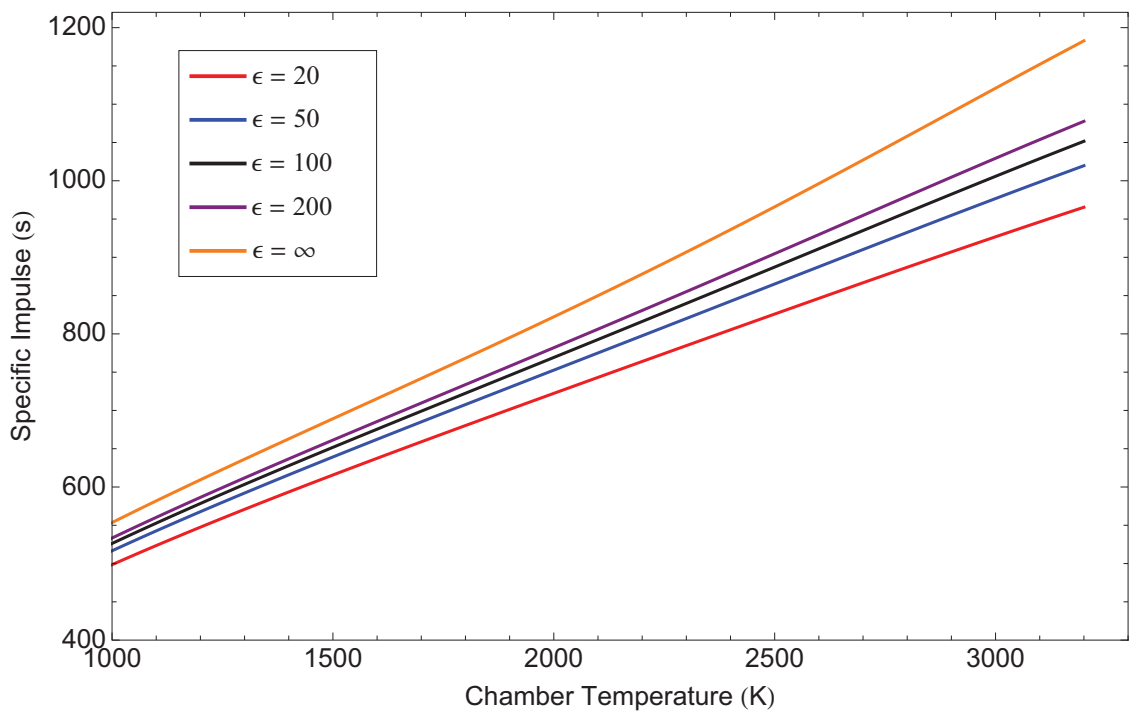

Figure 1. Temperature dependent specific impulse of a hydrogen cooled NTR engine for nozzle ratios ranging from 20 to infinity.

\section{A. Tungsten CERMET Fuels}

Compact NTR reactors require the use of fuel which is highly enriched in $\mathrm{U}^{235}$ and that can also sustain temperatures as high as $3000 \mathrm{~K}$ for the duration of a mission, where a typical mission to Mars requires 4 rocket burns for a cumulative burn time of approximately 2 hours. ${ }^{1}$ The fuel must also be able to retain the fissile material over the duration of the entire mission, resist hydrogen corrosion and erosion and prevent the migration of radioactive fission products into the hydrogen flow field. The United States of America conducted significant nuclear rocket engine testing during the ROVER/NERVA program of the 1960's which 
used carbide based fuel elements engrained with highly enriched uranium dicarbide $\left(\mathrm{UC}_{2}\right)$ particles, coated with zirconium carbide $(\mathrm{ZrC})^{3}$. ${ }^{4}$ The fuel elements were tested to temperatures as high as $2700 \mathrm{~K}$ with hydrogen outlet temperatures of approximately $2600 \mathrm{~K}$. Unfortunately the graphite matrix material had a very poor creep strength and had a very strong chemical affinity to hydrogen which led to significant fuels corrosion over the reactor lifetime. ${ }^{5}$ Carbon composite fuel elements were tested during the nuclear furnace program and did show improvement in the mass loss of fuel; however, the creep strength of the fuel was still quite low.

An alternative to graphite based nuclear rocket fuels are tungsten (W) based Ceramic-Metallic (CERMET) fuels where spherical particles of uranium dioxide $\left(\mathrm{UO}_{2}\right)$ are engrained in a tungsten matrix. ${ }^{6}$ Tungsten is a robust material which is resistant to hydrogen corrosion at very high temperatures and also has a very high creep strength. ${ }^{7}$ The high electron density of tungsten is also highly effective in retarding the migration of fission products and preventing their release into the hydrogen flow. $\mathrm{W}-\mathrm{UO}_{2}$ fuels fabricated in historical programs were fabricated such that the $\mathrm{UO}_{2}$ accounted for 10 to $60 \mathrm{vol} . \%$ of the fuel. ${ }^{8}$ Reducing the volume fraction of $\mathrm{UO}_{2}$ fuel can help improve the fuel stability; however a reduction in the fuel volume also has a detrimental effect on the reactor mass required to achieve the appropriate amount of excess reactivity. Fortunately, tungsten CERMET fuels were produced by the Argonne National Laboratory which contained $60 \mathrm{vol} . \% \mathrm{UO}_{2}$ and were successfully tested at temperatures as high as $3000 \mathrm{~K} .{ }^{6}$ The rest of this study will assume that fuels can and will be fabricated to $60 \mathrm{vol} . \% \mathrm{UO}_{2}$ which will minimize the reactor mass and maximize the rocket thrust to weight ratio.

Historical tungsten CERMET fuel fabrication programs were successful in fabricating fuel elements which were tested at refractory temperatures with negligible fuel mass loss; however, stabilizers were required to retard the formation and migration of liquid uranium within the fuel element. One of the most promising stabilizers was $\mathrm{Gd}_{2} \mathrm{O}_{3}$ (gadolinia) which is mixed into the $\mathrm{UO}_{2}$ fuel particles and sintered into a tungsten matrix. ${ }^{8}$ Fuels containing 0, 5 and 10 mol.\% gadolinia were tested as a function of thermal cycles to 2750 $\mathrm{K}$ and showed that gadolinia did indeed provide a more robust stability as the concentration increased. ${ }^{9}$ Figure 2 shows the fuel loss from a $\mathrm{W}-\mathrm{UO}_{2}$ fuel element as a function of thermal cycles and demonstrates the effect of $\mathrm{Gd}_{2} \mathrm{O}_{3}$ on the mass loss at $2750 \mathrm{~K}$. Unfortunately no data exists which relates the effects of gadolinia on fuel stability at temperatures higher than $2750 \mathrm{~K}$. The use of $10 \mathrm{~mol} \% \mathrm{Gd}_{2} \mathrm{O}_{3}$ is a conservative concentration that will most likely provide stability at temperatures as high as $3000 \mathrm{~K}$; however, gadolinium is a neutron absorber and will necessitate a larger and more massive reactor to achieve a given excess reactivity. The addition of $5 \mathrm{~mol} . \% \mathrm{Gd}_{2} \mathrm{O}_{3}$ will result in a smaller reactor than in the case of $10 \mathrm{~mol} . \%$; however, it is not certain that it will provide the required stability at temperatures as high as $3000 \mathrm{~K}$. At this point in time it is not known if a $\mathrm{W}-\mathrm{UO}_{2}$ CERMET fuel element will be fabricated with 5 or 10 mol.\% $\mathrm{Gd}_{2} \mathrm{O}_{3}$ and as such both concentrations are considered in the design of an NTR engine.

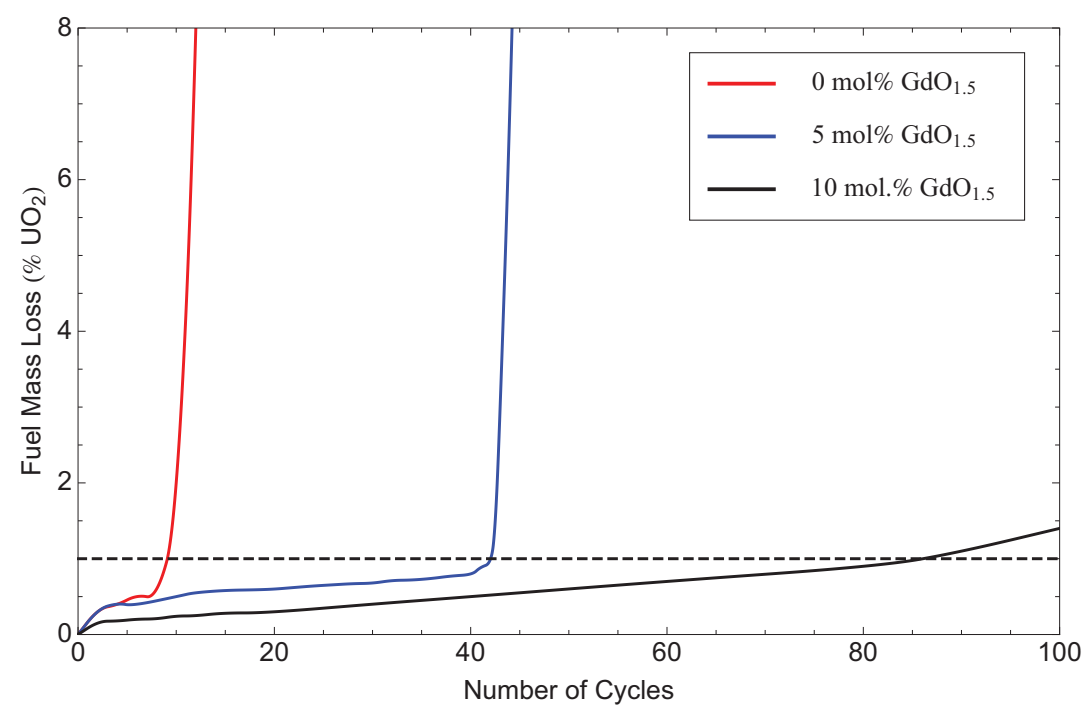

Figure 2. Experimental fuel loss from $\mathrm{W}-\mathrm{UO}_{2}$ fuel elements as a function of thermal cycles to $2750 \mathrm{~K}$ with $\mathrm{Gd}_{2} \mathrm{O}_{3}$ concentrations of 0,5 and $10 \mathrm{~mol} . \%$. 


\section{B. Reactor Configurations}

A Nuclear Thermal Propulsion reactor consists of six primary components, which are the axial neutron reflector, fission fuel, radial neutron reflector, inner and outer pressure vessels and control drums. The fuel elements and axial neutron reflector are combined into one item and are fabricated to be hexagonal in cross section.

For the purposes of this study the fuel hexagons are assumed to have a flat-to-flat thickness of $3.51 \mathrm{~cm}$ and a length that varies based on the reactor configuration. Fuel elements consist of of a homogenous mixture of 60 vol. $\% \mathrm{UO}_{2}$ and 40 vol.\% tungsten, where the $\mathrm{UO}_{2}$ can contain either 5 mol.\% or $10 \mathrm{~mol} \% \mathrm{Gd}_{2} \mathrm{O}_{3}$. Each fuel element is connected to a $20 \mathrm{~cm}$ long beryllium oxide $(\mathrm{BeO})$ neutron reflector with the exact same hexagonal cross section as the fuel element. For the purposes of this study the phrase fuel element refers to the combined fuel hex and axial reflector hex. Each fuel element consists of a number of coolant channels which can range from 37 to 127, which cuts through both the fuel element and the axial reflector. Each coolant channel is lined with a $0.009 \mathrm{~cm}$ thick cladding tube comprised of W-25wt.\%Re. Each fuel element is surrounded by a tungsten cladding sleeve with a hexagonal cross section that is $0.005 \mathrm{~cm}$ thick. Figure 3 shows a schematic of a fuel element with 127 coolant channels on the left and a fuel element with 91 coolant channels on the right.

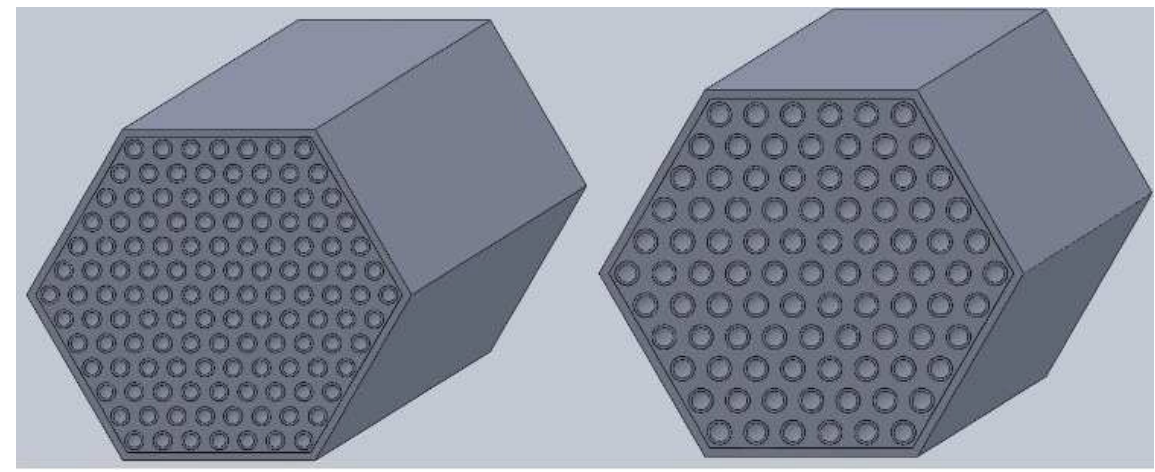

Figure 3. CAD diagrams of a fuel element with 127 coolant channels (left) and 91 coolant channels (right)

The fuel elements are arranged into a lattice array within a cylindrical titanium pressure vessel which is $0.635 \mathrm{~cm}$ thick. The fuel elements are pinned in place by a series of tungsten pinning rods and are also fastened to a header plate. The inner pressure vessel is surrounded by a beryllium (Be) radial neutron reflector which has a variable thickness depending on how many fuel elements are housed in the pressure vessel. Twelve control drums are housed within the radial reflector, each control drum consists of a titanium housing and centerline pin, a $\mathrm{BeO}$ fill and a outer sheath of enriched boron carbide $\left(\mathrm{B}_{4} \mathrm{C}\right)$ which encompasses a $120^{\circ}$ section of the drum. Figure 4 shows a CAD drawing of one possible reactor configuration which consists of 151 fuel elements 6 lattice rows deep where each fuel element contains $5 \mathrm{~mol} \% \mathrm{Gd}_{2} \mathrm{O}_{3}$; however, if the fuel consisted of $10 \mathrm{~mol} . \% \mathrm{Gd}_{2} \mathrm{O}_{3}$, the reactor would require 199 fuel elements 7 lattice rows deep. The reactor configuration investigated for this study is designed to produce $25,000 \mathrm{lb}_{f}$ of thrust at a specific impulse of 950 seconds, which requires a thermal power of $512 \mathrm{MW}$.

\section{Multiphysics Modeling}

Modern computational power and modeling tools allow for the design of fission reactors for power and propulsion applications with unprecedented coupling between neutronic, thermal hydraulic and stress analysis tools. Previous NTR engine analysis has been conducted with deterministic neutronic analysis tools and lumped heat capacity thermal hydraulic models ${ }^{10} .{ }^{11}$ While the combination of $\mathrm{S}_{N}$ and lumped heat capacity models do provide insight into the design and performance of an NTR engine, they lack the required detail for fabrication and ground testing in the modern engineering world. It is now possible to couple modern stochastic neutronics tools such as MCNP directly to state of the art Computational Fluid Dynamic programs (CFD) such as STAR-CCM+, which can provide detailed neutronic and thermal hydraulic analysis as well as stress analysis of an entire compact fission reactor. This analysis focused on the design of the fission core and the design of the appropriate surface area to volume ratio required to cool the fuel elements using 


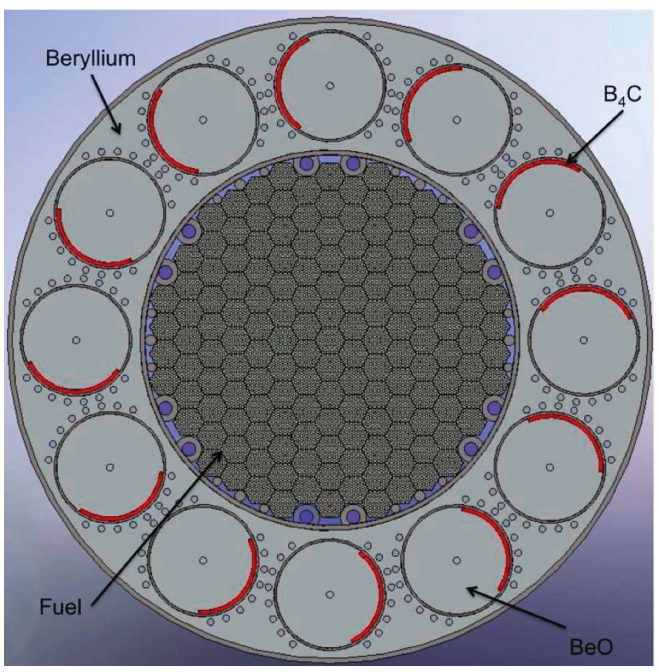

Figure 4. Top down view of a CAD diagram of a reactor configuration with 151 fuel elements and 12 control drums

a loosely couples suite of tools

\section{A. Monte Carlo Model}

The MCNP5 Monte Carlo program was selected to provide the neutronic inputs for the loosely coupled suite of tools. MCNP5 is a code written by the Los Alamos National Laboratory (LANL) which uses a a random number generator in combination with a suite os statistical probability distribution functions based on the energy dependent material cross sections to simulate the transport of neutrons and photons throughout a reactor geometry. ${ }^{12}$

The code requires a single source neutron location which was placed at the center of the computational geometry, from which the program creates 20,000 neutrons and propagates them through the geometry until they are terminated by leakage, absorption or a fission event. Each fission location is stored in the memory and is then used as a source location for fission neutrons in the next generation of neutrons. The computer code tracks the number of fission neutrons produced in each generation and compares it to the number of neutrons produced in the previous generation. The computer program continues to produce successive neutron generations until a user specified number of generations has been completed at which point it averages the ratio of generations to yield the average neutron multiplication number $\left(k_{e f f}\right)$, which is the average number of neutrons produced in one generation to the number produced in the previous generation. A value of $k_{e f f}$ less than one means the reactor is subcritical and can not sustain a fission chain reaction, a value greater than one means the reactor is supercritical and is increasing in power and a value equal to one means the reactor is critical and stable. The first 100 neutron generations are skipped in the calculation of $k_{e f f}$ in order to ensure a proper source distribution convergence.

Simultaneously while determining the value of $k_{e f f}$, the computer program can also determine the neutron flux at a given location within the geometry using a track length estimate which is then transformed into an energy deposition rate using either a modified F4 tally or an F6 tally. The energy deposition estimate assumes that the kinetic energy of the fission fragments and photons are all deposited locally. MCNP5 does not account for the energy deposited by delayed fissions; however, the delayed contribution of energy deposition is negligible when the reactor is in a critical or supercritical state.

\section{B. Thermal Hydraulics}

The Star-CCM+ version 5.02 Computational Fluid Dynamics (CFD) code was selected to provide an estimate of the steady state temperature distribution within a nuclear propulsion reactor. STAR-CCM+ is a finite volume solver code written by CD-Adapco which requires energy deposition rates at the centroid of finite volume cells which are used as a source term. ${ }^{13}$ The computer program then solves the Navier-Stokes equations shown in equations 3-5 using a $k-\epsilon$ model to determine the system turbulence. Within Equations 3 
through 6 the terms $\rho$ represents the fluid density, $\vec{u}$ represents the fluid velocity vector, $\tau$ represents a shear stress, $P$ represents the fluid pressure, $T$ represents the temperature, $k$ represents the thermal conductivity and $\dot{Q}$ represents the energy transfer rate.

$$
\begin{gathered}
\nabla \cdot(\rho \vec{u})=0 \\
\nabla \cdot(\rho \vec{u} \bigotimes \vec{u})+\nabla P=\nabla \cdot \vec{\tau} \\
\nabla \cdot\left[\rho\left(e+\frac{u^{2}}{2}\right) \vec{u}\right]+\nabla(\vec{u} P)=\nabla \cdot(\vec{u} \cdot \vec{\tau})+\nabla \cdot k \nabla T
\end{gathered}
$$

The solid equation was solved using the Laplacian heat conduction model demonstrated in Eq. 6 where the energy source term is extracted from the MCNP model. An emissive boundary condition was placed on the periphery of the reactor and an average emissivity of 0.8 was assumed.

$$
\dot{Q}=\nabla \cdot k \nabla T
$$

Great care was taken to optimize the mesh structure within the model in order to reduce the computational run time required to achieve convergence. The reactor model is reduced to a $1 / 6^{\text {th }}$ sector model which takes advantage of the azimuthal symmetry in the reactor cylinder. The semi-structured mesh was generated using GAMBIT such that the number of meshes ranged from 33.7 finite volume cells in the case of a 37 coolant channel hex model to 138 million finite volume cells in the case of the 127 coolant channel fuel hex. Computational run times range from less than 12 hours for the 37 coolant channel mode to 36 hours for the 127 coolant channel model. Figure 5 shows a cross section of the mesh structure within the 37 and 61 coolant channel models.

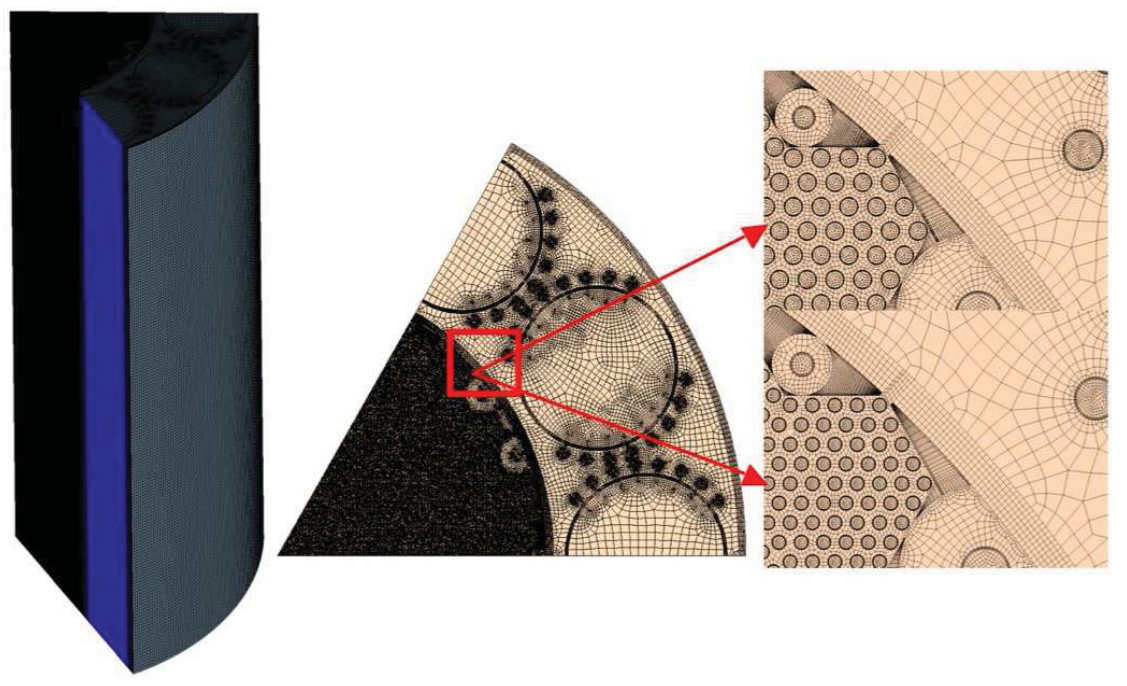

Figure 5. Schematic of the CFD meshed $1 / 6^{\text {th }}$ sector reactor with a zoom in on the fuel-pressure vessel interface for the 37 coolant channel (top) and 61 coolant channel (bottom) models.

The user is responsible for entering the appropriate thermophyscial and mechanical material properties into the STAR-CCM+ CFD code. Material properties for the beryllium, beryllium oxide, titanium and boron carbide were compiled from known literature databases and fit to polynomial curves and entered into the STAR-CCM+ code, ${ }^{14},{ }^{15},{ }^{16},{ }^{17},{ }^{18} \cdot{ }^{19}$ The thermal conductivity of a W-60 vol.\% $\mathrm{UO}_{2}$ CERMET fuel was estimated by the use of the Brugman model ${ }^{20}$ which was compared against experimental results. ${ }^{21}$ The specific heat of a dispersion fuel is determined by adding the specific heats of the fuel and tungsten materials in series based on the mass fractions of both, ${ }^{22}{ }^{7}$ Lastly, a FORTRAN 90 program was written to estimate the temperature and pressure dependent properties of equilibrium hydrogen over the range of $250 \mathrm{~K}$ to 5000 $\mathrm{K}$ and linked to the STAR-CCM+ code. The temperature and pressure dependent properties of hydrogen estimated by the FORTRAN program were compared to previous NASA models with good agreements, ${ }^{23} \cdot{ }^{24}$ 


\section{Coupled Model}

The purpose of the initial CERMET NTR engine study was to determine the optimum coolant channel surface area to fuel volume ratio $(\mathrm{SA} / \mathrm{V})$ required to cool the reactor to a peak temperature of $3000 \mathrm{~K}$. Determination of the optimum SA/V ratio required a computational model where the number of coolant channels, pitch distance within the fuel hex as well as coolant channel radius could be manipulated in a rapid fashion. In order to assist in the rapid development of new computational models where the material types and concentrations within the fuel as well as the fuel and reactor geometry could manipulated rapidly; a FORTRAN code called MCNTP (Monte Carlo Nuclear Thermal Propulsion) was written which autonomously creates MCNP5 input decks. The MCNTP code prompts the operator in an user friendly manner to enter in the appropriate $\mathrm{U}^{235}$ enrichment, fuel volume ratio, type of stabilizer, fuel length, hex flat-to-flat distance, number of coolant channels as well as many other parameters and then creates the entire reactor geometry.

The MCNP input deck is created to run in a kcode eigen value mode in order to determine the reactor neutron multiplication number. The code is also created with a segmented F6 tally over each fuel element in a single lattice row. Each fuel element is divided up into one centimeter segments and the average energy deposition rate is determined in each segment with the corresponding standard deviation. The output text file created by the MCNP 5 program is read by another FORTRAN program which extracts the axial power profile for each fuel element which produces a .CSV file listing the $x, y$, and $z$ coordinates in each fuel hex and the power deposition at that location. The FORTRAN program assumes azimuthal symmetry to determine energy deposition profile throughout the entire reactor from the one lattice row of fuel hexes. A single F6 tally is used in the radial neutron reflector which determines an average volumetric power density in the cell.

Prior to executing the MCNP5 program, the user manually creates a solid works CAD geometry of the reactor configuration which is identical to the MCNP geometry created in MCNTP. The user has to manually interface the CAD solid geometry to STAR-CCM+ and optimize the mesh structure using GAMBIT. Once the file has been interfaced and meshed, the user then enters the thermophysical properties into the STAR database as a polynomial equation or a series of discontinuous polynomial equations. The .CSV file created from the MCNP program is manually interfaced with the STAR program and then the program is initiated and allowed to run until the residuals are sufficiently low enough and the program has converged. Once the STAR program has ceased operation the temperature, pressure and stress data can be extracted and post processed for reduction. Figure 6 demonstrates the flow of information in the model used to generate the data for this paper. It should be noted that this version of the MCNP5 and STAR-CCM+ space reactor simulation is not a fully coupled code as data is not autonomously exchanged between programs and their is no feedback mechanism from the STAR program back into the MCNP program. However, the thermal expansion coefficient of the fuel is expected to be on the order of $10^{-6} \mathrm{~K}^{-1}$ and as such the role of fuel expansion on the reactivity of the system is expected to be negligible. Also the doppler broadening present in systems highly enriched in $\mathrm{U}^{235}$ is negligible and as such, the change in absorption and fission cross sections is expected to be small. Figure 6 demonstrates the flow of information in this first version of the space reactor code suite.

\section{Multiphysics Results}

\section{A. Reactor System Neutronics}

\section{Effects of Cladding Sleeves on Reactor Control}

Figure 3 demonstrates the cross sectional geometry of a fuel element to include the W-25\%Re cladding tubes and the tungsten cladding sleeves. Unlike the cladding tubes, the cladding sleeves surround the fuel element and as such can add some neutron reflection to the system. The reflection of neutrons back into individual fuel elements can be detrimental to reactor control. In a typical nuclear propulsion reactor, a fraction of the neutron population can leak from the fission core into the beryllium radial reflector. Some of the leaking neutrons can be captured by the beryllium and undergo a $(n, 2 n)$ reaction where two neutrons are isotropically ejected at back to back angles for every neutron absorbed. A percentage of these $(n, 2 n)$ neutrons are ejected back into the fission core where they contribute to the neutron population causing fission events. The boron carbide control drums can be rotated such that the $\mathrm{B}_{4} \mathrm{C}$ is moved closer to the fission core at which point it absorbs neutrons before they can undergo $(n, 2 n)$ interactions in the beryllium, which reduces the neutron population in the fission core to a point where the system becomes subcritical. 


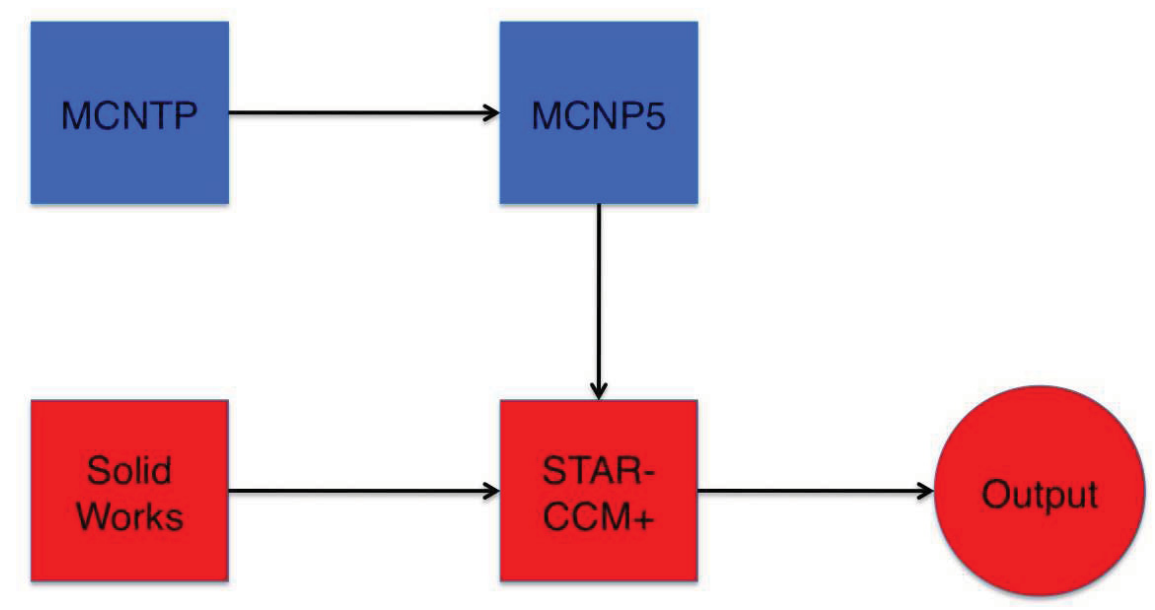

Figure 6. Diagram demonstrating the flow of information in the combined MCNP5-STAR-CCM+ space reactor simulation package.

The tungsten cladding sleeves can have a very advantageous effect on optimizing the fuel stability; however, if the tungsten sleeve prevents neutrons from diffusing into the reflector it can make it very difficult to bring the system to a subcritical state. In steady state conditions the neutrons population in the core is maintained by reflection from the tungsten sleeve; however, if the neutrons are reflected before they can interact with the $\mathrm{B}_{4} \mathrm{C}$, shutting the reactor down can be difficult. A sample case was ran, where the reactor system was computationally built to consists of $60 \mathrm{vol} . \% \mathrm{UO}_{2}$ within the fuel and the fuel was mixed with 5 mol.\% $\mathrm{Gd}_{2} \mathrm{O}_{3}$. Two cases were executed where in one case the fuel elements were surrounded by a cladding sleeve $0.005 \mathrm{~cm}$ thick and in the other case no cladding sleeves were used. In this initial case, the fuel elements for both reactor configurations consisted of 37 coolant channels per fuel hex. Each reactor system was designed to have 6 lattice rows of fuel elements totaling 151 and the length of each reactor configuration was varied such that both systems had approximately the same drums out neutron multiplication number. The combined MCNTP and MCNP5 code was used to determine the value of $k_{\text {eff }}$ as a function of drum rotation angle between 0 and $180^{\circ}$ for both reactor configurations. The reactor configuration where the cladding sleeve is incorporated was found to have a drum worth of $-4.229 \% \Delta k / k$ and the configuration without the cladding sleeve was found to have a drum worth of $-5.816 \% \Delta k / k$. Figure 7 demonstrates the drum angle dependent neutron multiplication number of a configuration with and without tungsten cladding sleeves.

The use of a tungsten cladding sleeve was found to reduce the reactivity control available in the control drum. It is not known at this time how much shutdown margin is required for a fast spectrum space reactor; however, the use of the cladding sleeves can retard the ability of the control drums to shut the reactor down. It may be possible to fabricate the peripheral fuel elements in a manner where the $\mathrm{UO}_{2}$ relative density is reduced in an effort to reduce fuel loss such that a cladding sleeve is not needed in the peripheral fuel elements, but will be used in the inner fuel elements. Reducing the $\mathrm{UO}_{2}$ density will necessitate an increase in the reactor length and mass to achieve a desired excess reactivity; however, it could increase the control drum effectiveness by allowing more neutrons to leak into the radial reflector. Future computational experiments will investigate a different fuel configuration for the peripheral elements and their effects on reactor control.

\section{Reactor Volumetric Power Profile}

The exact dimensions of a reactor will effect the magnitude of the volumetric energy deposition profile within the fission core; however the basic geometry is still the same. As an initiating point, the geometry of a slightly modified XNR-2000 reactor concept was chosen as a baseline. ${ }^{10}$ The XNR-2000 reactor design consists of 151 fuel elements, each with 37 coolant channels with a radius of $0.1778 \mathrm{~cm}$ and lined with a $0.025 \mathrm{~cm}$ thick W-25\%Re cladding tube. The modified XNR-2000 core had a coolant channel surface area to fueled volume ratio of 7.0189. Each fuel element was surrounded with a $0.025 \mathrm{~cm}$ thick tungsten cladding sleeve. The reactor has a length of $90.69 \mathrm{~cm}$ and was surrounded by a $16.45 \mathrm{~cm}$ thick beryllium neutron reflector 


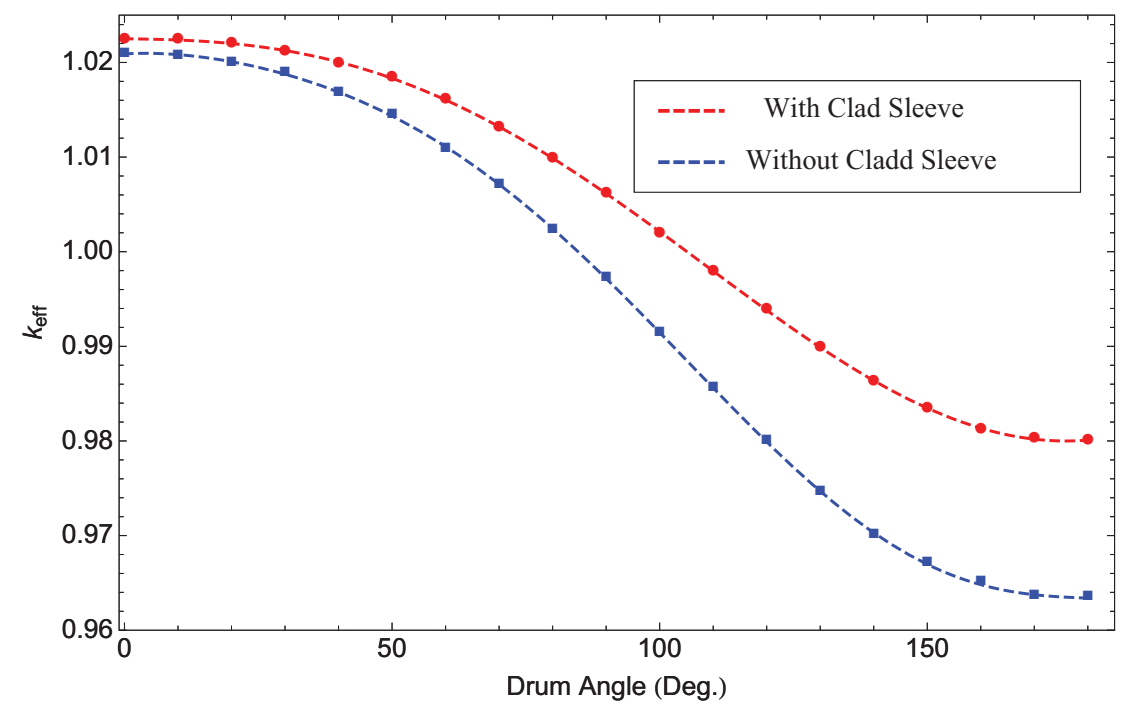

Figure 7. Plot of the neutron multiplication number as a function of control drum rotation angle for a reactor configuration where fuel elements are surrounded by a tungsten cladding sleeve and without a cladding sleeve.

and 12 control drums lined with a $60^{\circ}$ sheath of $\mathrm{B}_{4} \mathrm{C}$. Each fuel element consisted of a $20 \mathrm{~cm}$ long $\mathrm{BeO}$ axial neutron reflector and an inner and outer pressure vessel of titanium. The reactor system had a drums out neutron multiplication number of 1.025 and a control drum worth of $-4.04 \% \Delta k / k$. The MCNP5 code was created using the MCNTP program and ran using F6 tallies to determine the neutron heating, gamma heating and fission heating within the core as well as the neutron and gamma heating within the axial and radial reflectors. Figure 8 demonstrates a volumetric energy deposition profile within the fission core as a function of radius $(r)$ and axial position $(Z)$ taken from the data extracted from the MCNP5 program for the modified XNR-2000 reactor system. A drop in the power density is clearly seen at the axial position of $20 \mathrm{~cm}$, which represents the interface between the fuel and the axial reflector region. The power profile drops in a nearly cosine function up to a radial position of $20 \mathrm{~cm}$, where the power begins to increase again due to the influence of neutrons being reflected by the beryllium reflector and the tungsten cladding sleeves.

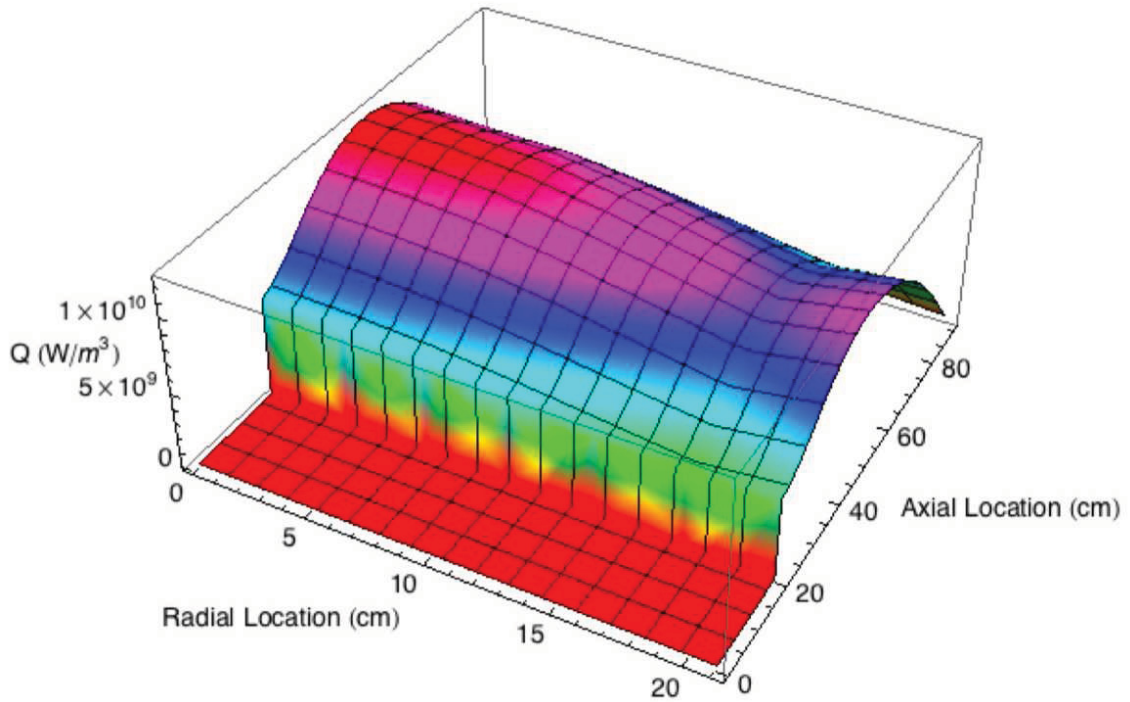

Figure 8. Volumetric energy deposition rate profile for the modified XNR-2000 reactor system as a function of radius and axial length in units of $W / \mathbf{m}^{3}$ 


\section{B. Reactor System Thermal Hydraulics}

The volumetric power deposition in both the core and the radial reflector were transferred to the STAR$\mathrm{CCM}+$ code via a .CSV file and the program was initiated. The centerline radial energy deposition profile was also used to develop a radial mass flow rate profile in an attempt to flatten the temperature profile and maximize the average hydrogen outlet temperature. Figure 9 demonstrates the method of producing a radial mass flat profile. The energy deposition profile was used to determine a mass flow rate per fuel hex which was divided between each coolant channel in the fuel hex in a manner where the total mass flow rate summed to the $12.05 \mathrm{~kg} / \mathrm{s}$ required to produce $25,000 \mathrm{lb}_{f}$ of thrust at 940 seconds of specific impulse. The diagram on the left side of Figure 9 shows a $1 / 6^{\text {th }}$ sector of the fission core where rows of fuel hexes are labeled as ring number, the right side plot demonstrates the mass flow rate per ring.
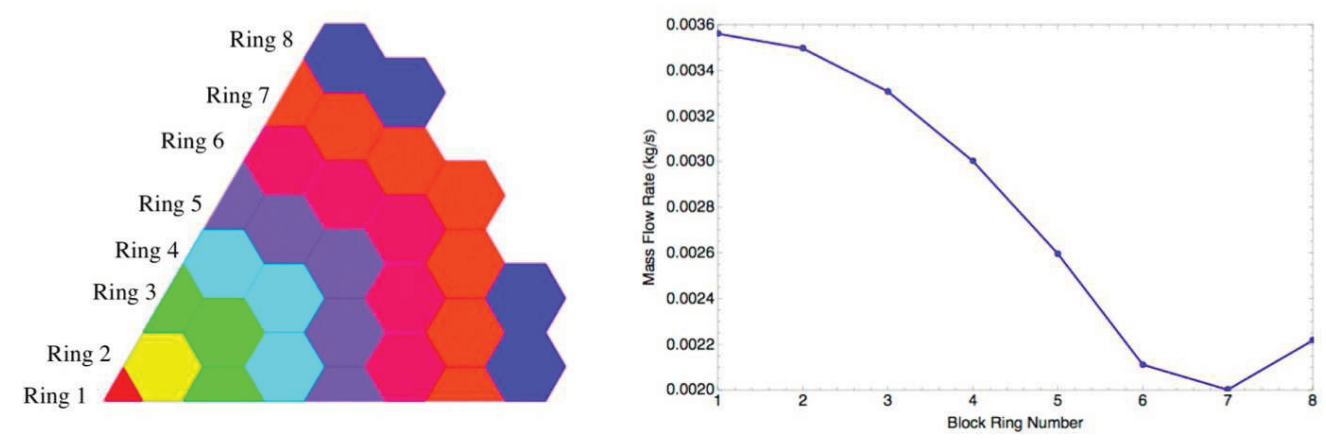

Figure 9. Radial mass flow rate profile based on the energy deposition profile.

The modified XNR-2000 NTR engine was found to have a coolant channel surface area to fueled volume ratio that was far to small to maintain a peak fuel temperature of $3000 \mathrm{~K}$ or less. The peak fuel temperature was found to be just slightly below $3700 \mathrm{~K}$, which is nearly 40 degrees above the melting point of tungsten. Figure 10 shows the top down temperature profile predicted by the STAR-CCM+ computer code. While the peak temperature is to high for an NTR engine of this type, the code did show the relatively flat temperature profile produced by radially varying the mass flow rate.

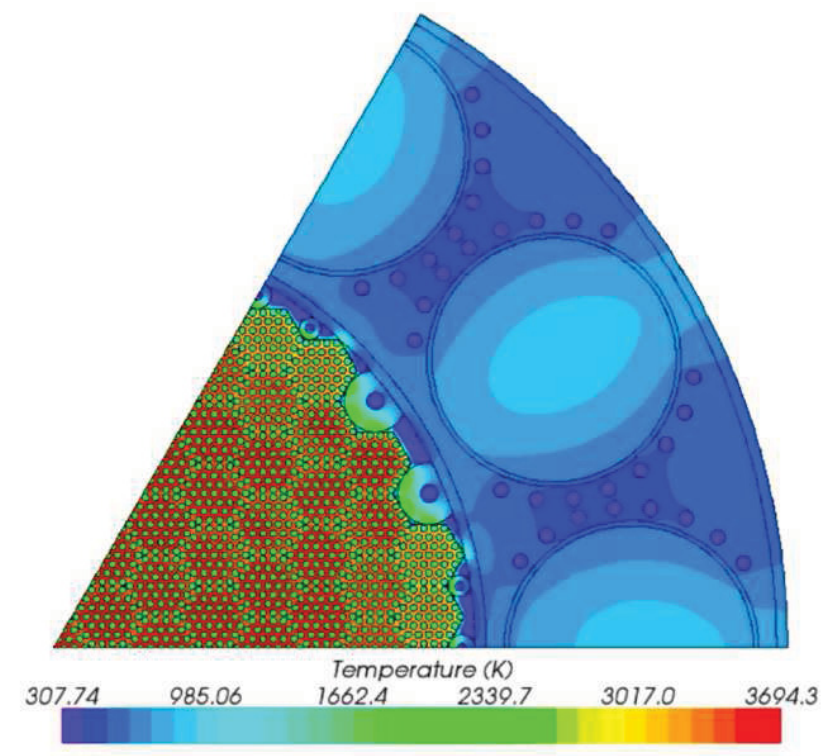

Figure 10. Top down view of the temperature profile predicted by the STAR-CCM+ code for the modified XNR-2000 NTR engine.

The fission core was redesigned to have 61 coolant channels per fuel hex which is a surface area to volume ratio of 9.9837, 91 coolant channels per fuel hex (SA/V ratio of 12.458) and 127 coolant channels per fuel 
hex (SA/V ratio of 14.140) The cladding thickness in each case was reduced from $0.025 \mathrm{~cm}$ to $0.009 \mathrm{~cm}$ and the cladding sleeve thickness was reduced to $0.005 \mathrm{~cm}$. The $\mathrm{UO}_{2}$ volume ratio was maintained at $60 \%$ and the $\mathrm{Gd}_{2} \mathrm{O}_{3}$ molar fraction was maintained at $5 \%$. The axial neutron reflector was maintained at a length of $20 \mathrm{~cm}$ and the radial reflector and drum configuration was maintained to be the same as the modified XNR2000 design. The dimensions core length for each case was adjusted to maintain a drums out $\mathrm{k}_{\text {eff }}$ of 1.025 using the MCNP5 computer code. Unfortunately funding for this study ran out before all configurations could be tested in the STAR-CCM+ code; however, the 61 and 91 coolant channel configurations were ran to convergence. The 61 coolant channel configuration had a peak temperature of $3414 \mathrm{~K}$ and the 91 coolant channel configuration had a peak temperature of $3211 \mathrm{~K}$. None of the configurations tested met the criteria of a peak temperature at or below $3000 \mathrm{~K}$; however, based on the trend it is likely that the 127 coolant channel configuration would have had a peak temperature at or below $3000 \mathrm{~K}$.

Figure 11 shows a plot which demonstrates the peak fuel temperature predicted for a CERMET NTR engine as a function of surface area to volume ratio for a $\mathrm{W}-\mathrm{UO}_{2}$ fuel which consists of $60 \mathrm{vol} . \% \mathrm{UO}_{2}$ and 5 mol.\% $\mathrm{Gd}_{2} \mathrm{O}_{3}$. The experiment was also conducted for a reactor system where the fuel consisted of 10 mol.\% $\mathrm{Gd}_{2} \mathrm{O}_{3}$. The reactor configuration consisting of 10 mol.\% $\mathrm{Gd}_{2} \mathrm{O}_{3}$ required a larger volume to reach the drums out $\mathrm{k}_{\text {eff }}$ of 1.025 and thereby had a lower power density. The decrease in power density reduced the surface area to volume ratio to an amount where 91 coolant channel per fuel hex were sufficient to cool the reactor to a peak temperature of $3000 \mathrm{~K}$ which is also shown in Figure 11. Figure 12 demonstrates a orthogonal view of the temperature profile predicted for an engine which has 91 coolant channels per fuel hex.

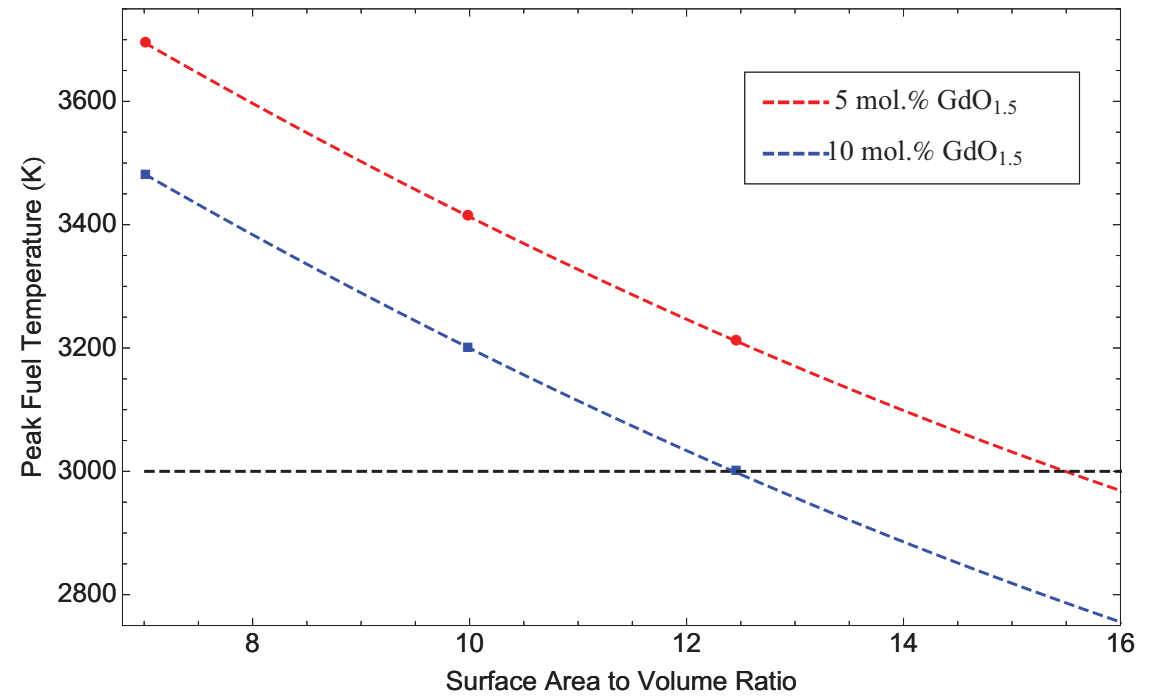

Figure 11. Top down view of the temperature profile predicted by the STAR-CCM+ code for the modified XNR-2000 NTR engine.

\section{Reactor Performance}

The final fuel element configuration for each reactor type (5 and 10 mol.\% $\mathrm{Gd}_{2} \mathrm{O}_{3}$ ) were used to determine the neutron multiplication numbers with the control drums rotated in and out as well as a situation where the reactor is submerged in fresh water with the coolant channels flooded in a drums out state. The delayed neutron fraction $(\beta)$ as well as the average number of neutrons emitted per fission event $(\nu)$ were determined. Each reactor configuration was designed to have a thrust of $25,000 \mathrm{lb}_{f}$ and a specific impulse of 950 seconds. The weight, thrust to weight ratio and power density were also determined for each conceptual configuration. Table 1 demonstrates all of the performance parameters for the two different NTR engine configurations and assumes the balance of plant which includes nozzle, turbopumps, actuators, detectors and misc. items to have a mass of $700 \mathrm{~kg}$ on top of the reactor mass.

Figure 13 shows the neutron multiplication numbers for both configurations as a function of control drum rotation angle ranging from 0 to 180. 


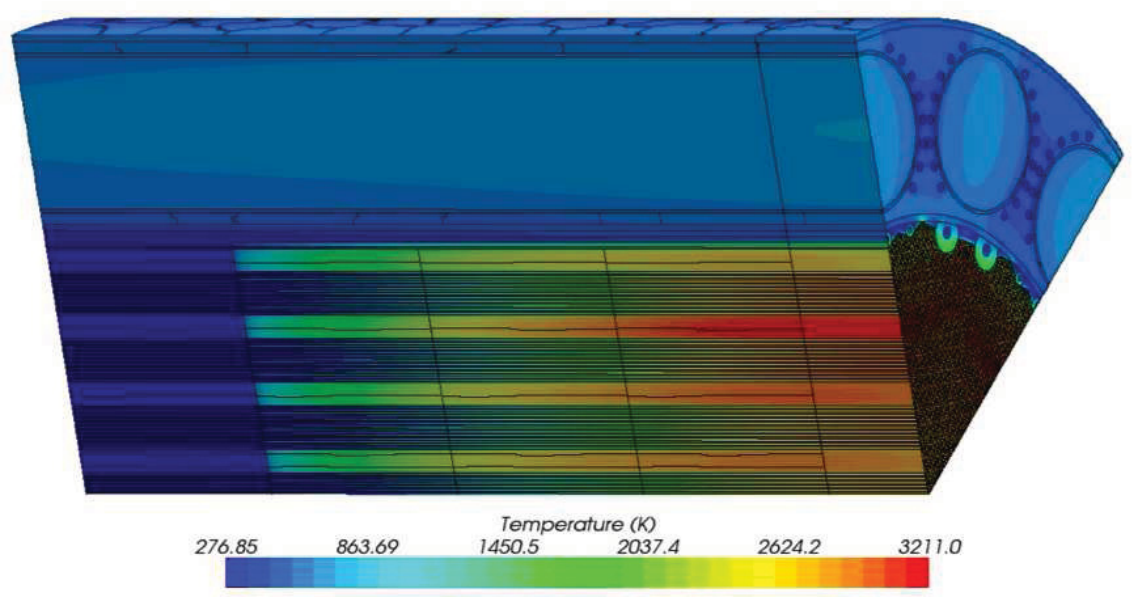

Figure 12. Orthogonal view of the temperature profile predicted by the STAR-CCM+ code for an CERMET NTR engine which has as coolant channel surface area to fueled volume ratio of 12.458 .

Table 1. Neutronic and performance parameters for a reactor fueled with W-60vol. $\% \mathrm{UO}_{2}$ fuel elements consisting of 5 and $10 \mathrm{~mol} . \% \mathrm{Gd}_{2} \mathrm{O}_{3}$.

\begin{tabular}{lcc} 
& $5 \mathrm{~mol} . \% \mathrm{Gd}_{2} \mathrm{O}_{3}$ & $10 \mathrm{~mol} . \% \mathrm{Gd}_{2} \mathrm{O}_{3}$ \\
\hline $\mathrm{k}_{\text {eff }}$ (open) & 1.02508 & 1.02462 \\
$\mathrm{k}_{\text {eff }}$ (closed) & 0.98571 & 0.98741 \\
$\mathrm{k}_{\text {eff }}$ (submerged) & 0.92154 & 0.92087 \\
$\beta$ & 0.0066898 & 0.00647537 \\
$\nu$ & 2.500 & 2.48 \\
Mass $(\mathrm{kg})$ & 2761 & 3200 \\
$\mathrm{~T} / \mathrm{W}$ & 4.107 & 3.543 \\
$\mathrm{P}_{d}\left(\mathrm{GW} / \mathrm{m}^{3}\right)$ & 9002 & 6228
\end{tabular}

\section{Conclusions}

A basic model was produced which consolidated the capabilities of MCNP5 and the STAR-CCM+ code to simulate a Nuclear Thermal Rocket propulsion reactor. The MCNP5 code was used to determine the excess reactivity within the reactor as well as energy deposition profile within the reflector and fission core. The energy deposition profile was imported to STAR-CCM+ code which then determined the steady state temperature profile within the core assuming a hydrogen flow of the appropriate mass flow rate. The combined codes were not fully coupled, but were still successfully used to determine the appropriate coolant channel surface area to fueled volume ratio required to cool the core to a maximum temperature of $3000 \mathrm{~K}$. If the fuel elements consist of $60 \mathrm{vol} . \% \mathrm{UO}_{2}$ and $40 \mathrm{vol} . \% \mathrm{~W}$, with the $\mathrm{UO}_{2}$ consisting of $5 \mathrm{~mol} . \% \mathrm{Gd}_{2} \mathrm{O}_{3}$, then only 6 lattice rows of fuel hexes are required assuming a flat-to-flat distance of $3.51 \mathrm{~cm}$, and 127 coolant channels per fuel hex adding up to a surface area to volume ratio of 14.8. In a configuration where $10 \mathrm{~mol} \%$ $\mathrm{Gd}_{2} \mathrm{O}_{3}$ is used, then the reactor has a larger volume, requiring 7 lattice rows of fuel hexes and 91 coolant channels per fuel hex. Each of the configurations used W-25\%Re cladding tubes which were $0.009 \mathrm{~cm}$ thick tungsten cladding sleeves $0.005 \mathrm{~cm}$ thick. The reactor masses ranged from $2761 \mathrm{~kg}$ at $5 \mathrm{~mol} . \% \mathrm{Gd}_{2} \mathrm{O}_{3}$ to $3200 \mathrm{~kg}$ at $10 \mathrm{~mol} . \% \mathrm{Gd}_{2} \mathrm{O}_{3}$, which yields a thrust to weight ratio which ranges from 3.543 to 4.107 and a power density which ranges from $6228 \mathrm{GW} / \mathrm{m}^{3}$ to $9002 \mathrm{GW} / \mathrm{m}^{3}$. 


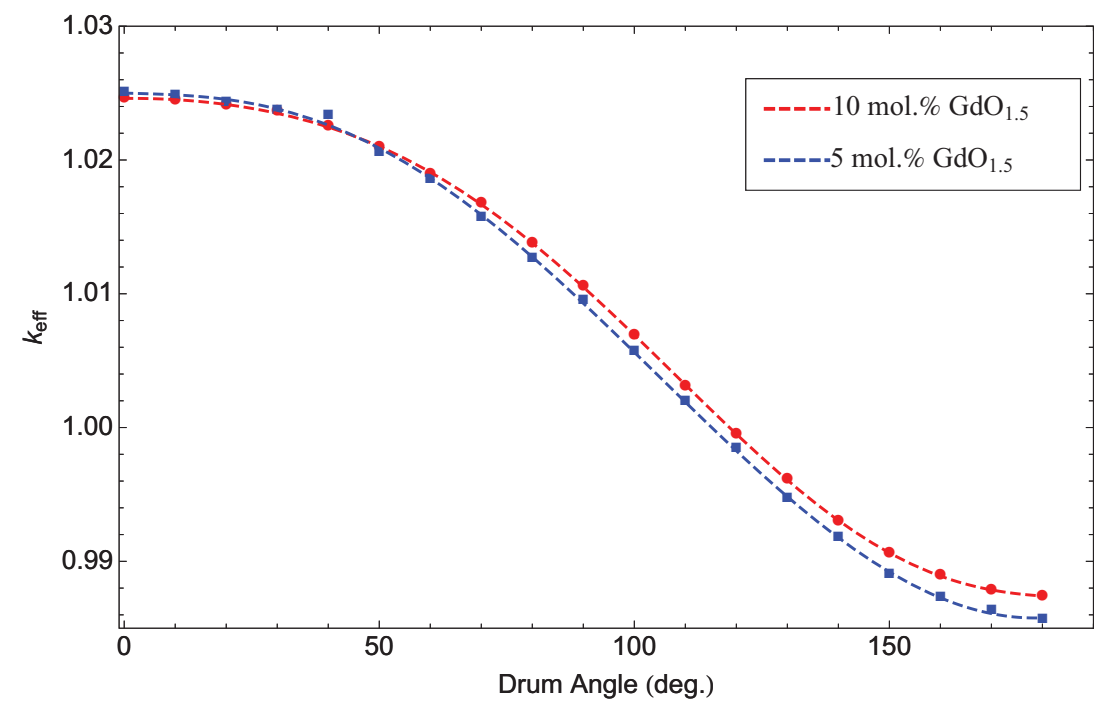

Figure 13. Neutron multiplication number for reactor configurations consisting of 5 and $10 \mathbf{m o l}^{2} \mathrm{Gd}_{2} \mathrm{O}_{3}$ as a function of control drum rotation angle.

\section{Future Work}

Future work will focus on transforming the current suite of codes into a fully coupled system, where the thermal expansion of materials can be fed from the STAR-CCM+ code back into the MCNP5 program in an attempt to characterize the thermal feedback mechanisms on neutronic behavior. The effect of cladding tube surface roughness will be evaluated over a range of possible values which may be seen in a flight reactor. Also, the size of the fuel hex flat-to-flat distance will be manipulated in an effort to determine a size which produces a minimum stress, while still maintaining the appropriate coolant channel surface area to fueled volume ratio. Within the next year the authors of this paper hope to begin a more robust structural analysis in an effort to determine the optimum cladding thickness from both a fission product migration and structural point of view.

\section{References}

${ }^{1}$ Drake, B. G., "Human Exploration of Mars, Design Reference Architecture 5.0," Nasa/sp-2009-566, National Aeronautics and Space Administration., Houston, TX, July 2009.

${ }^{2}$ Sutton, G. P. and Biblarz, O., Rocket Propulsion Elements, John Wiley and Sons, 2001.

${ }^{3}$ Angelo, J. A. and Buden, D., Space Nuclear Power, Orbit Book Co., 1985.

${ }^{4}$ Lyon, L. L., "Performance of (U,Zr)C-Graphite (Composite) and of (U,Zr)C (Carbide) Fuel Elements in the Nuclear Furnace 1 Test Reactor," La-5398-ms, Los Alamos Scientific Laboratory, Los Alamos, NM, Sept. 1973.

${ }^{5}$ Genk, M. S. E. and Pelaccio, D. G., "A Review of Nuclear Thermal Propulsion Carbide Fuel Corrosion and Key Issue," Nasacr-197533, National Aeronautics and Space Administration, Albuquerque, NM, 1994.

${ }^{6}$ Bhattacharyya, S. K., "An Assessment of Fuels for Nuclear Thermal Propulsion," Anl/td/tm01-22, Argonne National Laboratory, Argonne, Ill, Dec. 2001.

${ }^{7}$ Webb, J. A. and Charit, I., "Physical and Mechanical Properties of W-Re Alloysd," Tech. rep., Idaho National Laboratory, Idaho Falls, ID, 2011.

${ }^{8}$ Burkes, D. E., Wachs, D. M., Werner, J. E., and Howe, S. D., "An Overview of Current and past W-UO 2 CERMET Fuel Fabrication Technology," Inl/con-07-12232, Idaho National Laboratory, Idaho Falls, ID, June 2007.

${ }^{9}$ Kruger, G., Public Interview, General Electric Company, Published on NASA Tech. Report Server, N92-11096, 1992. 1992.

${ }^{10}$ Parsley, R. C., "Advanced Propulsion Engine Assessment based on a CERMET Reactor," N93-26919, Pratt and Whitney,

${ }^{11}$ Hussey, C. C., Woike, O., and Zwick, J. W., "Conceptual Mechanical Design for a Fast Energy Spectrum Nuclear Rocket Engine," Ge-tm-65-5-13, General Electric Company, 1965.

${ }^{12}$ Team, X.-. M. C., "MCNP - A Genral Monte Carlo N-Particle Transport Code, Version 5, Volumes I-III," La-ur-03-1987, Los Alamos National Laboratory, Los Alamos, NM, 2003.

${ }^{13}$ CD-Adapco, "STAR-CCM+ Version 5.02 Users Guide," Users manual, CD Adapco, 2009.

${ }^{14}$ Lyde, D., Handbook of Chemistry and Physics, Academic Press, 2006. 
${ }^{15}$ Carniglia, S. C., "Fabrication and Properties of Dense Beryllium Oxide," Journal of Nuclear Materials, Vol. 4, No. 2, 1961, pp. 165-176.

${ }^{16}$ Goldberg, A., "Atomic, Crystal, Elastic, Thermal, Nuclear and other Properties of Beryllium," Tech. rep., Lawrence Livermore National Laboratory.

${ }^{17}$ Team, L. M. D., "Space Reflector Materials for a Prometheus Application," B-mt(spme)-23, Knolls Atomic Power Laboratory, West Mifflin, Pa, Jan. 2006.

${ }^{18}$ Thevenot, F., "Boron Carbide, A Comprehensive Review," Journal of the European Society, Vol. 6, 1990, pp. $205-225$.

${ }^{19}$ Medwick, P. A., Fischer, H. E., and Pohl, R. O., "Thermal Conductivity and Specific Heat of Boron Carbides," Journal of Alloys and Compounds, Vol. 203, 1994, pp. 67-75.

${ }^{20}$ Miller, J. V., "Estimating Thermal Conductivity of CERMET Fuel Materials for Nuclear Reactor Applications," Tech. rep., National Aeronautics and Space Administration.

${ }^{21}$ Grossman, L. N., "Thermal Conductivity of Coated Particle $\mathrm{UO}_{2}$-Tungsten CERMETS," Tech. rep., National Aeronautics and Space Administration.

${ }^{22}$ Fink, J. K., "Thermophysical Properties Review of Uranium Dioxide," Journal of Nuclear Materials, Vol. 279, 2000, pp. $1-18$.

${ }^{23}$ Kubin, R. and Presley, L., "Thermodynamic Properties and Mollier Chart for Hydrogen to 10,000 K and 1.01325. $10^{8}$ N/m²," Nasa sp-3069, National Aeronautics and Space Administration, Jan. 1971.

${ }^{24}$ McCarty, R. and Weber, L., "Thermophysical Properties of Parahydrogen from the Freezing Liquid Line to 5000 R for Pressures to 10,000 psia," Nbs-617, National Bureau of Standards, Jan. 1972. 